\title{
Espectacularidad, esteticismo y decadencia. Las corridas de toros en una crónica de viaje de José Ingenieros ${ }^{1}$
}

\author{
Cristina Beatriz FERNÁNDEZ \\ Universidad Nacional de Mar del Plata (UNMDP)-CONICET. Argentina
}

\begin{abstract}
RESUMEN
El presente artículo analiza la crónica "La morfina en España", de José Ingenieros, sobre las corridas de toros, estructurada sobre dos ejes: uno estético y otro de corte sociológico, explicación que es tributaria del discurso sobre el orden social escrito en el lenguaje de las ciencias biológicas, como lo indica el título de la crónica, sin renunciar al placer estético del espectáculo.
\end{abstract}

Palabras clave: crónica, corrida de toros, esteticismo, cientificismo.

Showiness, aestheticism and decadence. The bullfights in a chronicle of Jose Ingenieros's trip

\begin{abstract}
The present article analyzes the chronicle "La morfina en España", of Jose Ingenieros, on the bullfights, structured on two axes: the aesthetic and different one of sociological cut, explanation that is tributary of the speech on the social order written in the language of the biological sciences, as the title of the chronicle indicates it, without resigning the aesthetic pleasure of the spectacle.
\end{abstract}

Keywords: Chronicle, Bullfight, Aestheticism, Scientificism.

SUMARIO: 1. La mirada estética. 2. La mirada cientificista. 3. Comentario final.

Y comprendí el alma de la España que no perece, la España reina de vida, emperatriz del amor, de la alegría y de la crueldad; la España que ha de tener siempre conquistadores y poetas, pintores y toreros. (Rubén Darío)

${ }^{1}$ Este trabajo forma parte del proyecto de investigación "Estética modernista y cultura científica en las crónicas de viaje de dos autores latinoamericanos: José Ingenieros y Justo Sierra", financiado mediante un subsidio PIP del CONICET. 
En el año de 1905, José Ingenieros (1876-1925) debió viajar a Europa para representar a la Argentina ante el V Congreso Internacional de Psicología que se desarrolló en Roma, después de lo cual recorrió varias capitales de ese continente, en un tour que se extendió por más de un año, hasta octubre de 1906. En el transcurso de dicho viaje, escribió "crónicas" o "correspondencias" -para emplear sus mismos términos- que fueron publicadas en el diario La Nación de Buenos Aires. Aunque posteriormente fueron recogidas en forma parcial y con modificaciones -en algunos casos, muy significativas- en los libros Italia en la ciencia, en la vida y en el arte (Valencia, 1906), Al margen de la ciencia (1908) y en sus obras completas, nos basamos, para este trabajo, en la edición original, que compulsamos en las páginas del diario y editamos recientemente.

En la mirada de este médico alienista, cada lugar del recorrido se convirtió en un pequeño viaje con fines específicos. Entre esos lugares se encuentra Madrid, ciudad desde la cual fue remitida la única crónica concerniente a España. Se trata de "La morfina en España", cuyo título hace referencia, aunque a primera vista sea difícil deducirlo, a una corrida de toros. La misma crónica aparece en el libro Al margen de la ciencia y en las obras completas, sólo que en estas dos últimas cambia ligeramente el título por "La morfina de España", además de haberse producido algunas variantes menores en su redacción.

No deja de ser curioso que Ingenieros, médico psiquiatra, socialista, progresista, se concentre, en la única crónica fechada desde España, en el espectáculo tradicional de una corrida de toros, difícilmente vinculable con sus intereses cientificistas y modernizadores. No obstante, el autor convierte la crónica, a partir de la descripción inicial del espectáculo, en oportunidad para una disertación ideológica en dos direcciones: una estética y otra socio-biológica, siempre en el marco de ese "ambiente espiritual del 900", fuertemente signado por el pensamiento positivista (Real de Azúa, 1987). Analizaremos a continuación cada una de esas perspectivas.

\section{La mirada estética}

Comenzaremos por la cuestión del tema elegido, que podría parecer improcedente entre el resto de las crónicas de viaje de Ingenieros, las cuales se caracterizan por un tono celebratorio de la modernidad europea: paseos por las grandes capitales, congresos científicos, espectáculos novedosos, visitas a políticos y escritores del momento, etc. Recordemos que nuestro autor se ubica claramente en el marco ideológico de los sectores reformistas en la Argentina del entresiglo XIX-XX. Entre los rasgos que distinguieron el accionar de estos sectores reformistas se destacan la conjugación de su actividad profesional con la vida académico-intelectual y la vocación de intervención política, la ideología de sesgo progresista -muy frecuentemente, anticlerical-, la preocupación por resolver las cuestiones sociales en el marco de la legalidad y el afán de insertar a la Argentina en el contexto moderno 
internacional (Zimmermann, 1995: 15 y ss.). El viaje a Europa de Ingenieros significó, más allá de sus funciones oficiales, una experiencia formativa que colaboró en su acceso a la modernidad, tan deseada para el ámbito argentino por intelectuales como él. En efecto, dada la interdependencia entre progreso y civilización, característica de la ideología imperante y que en gran medida suscribía Ingenieros, se suponía que el progreso había brindado al habitante urbano de la Europa moderna tanto su gusto por las bellas artes y la música como su comprensión científica y racional del mundo, lo cual derivaba en el rechazo de la violencia, la crueldad, la superstición y el despotismo político (Herman, 1998: 34). A primera vista, entonces, reseñar un espectáculo como la corrida no parece encajar del todo en su plataforma ideológica, sino más bien en un programa estético que privilegie el color local, como podría ocurrir en el caso de un viajero romántico o costumbrista. Sabemos que las escenas costumbristas o los motivos que podían resultar exóticos eran parte del acervo temático de la crónica e incluso se ha señalado que el cuadro de costumbres es uno de los antecedentes de ese tipo discursivo (Rotker, 2005: 123124; Jiménez, 1993: 546-547) y, claro está, pocos asuntos ofrecían material más típico o costumbrista que una corrida de toros en España.

De hecho, las filiaciones literarias del tema son bastante claras en esta crónica. Ella se inicia, sintomáticamente, con la alusión a un verso de Manuel Machado: "Oro, seda, sangre y sol". Esta es una de las primeras referencias de orden literario que aparecen, significativa, ya que se trata de un autor modernista de cuyo círculo madrileño formó parte Ingenieros, además de que ambos tenían amigos comunes tanto en Madrid como en París, entre los cuales destacan las figuras de Rubén Darío y Enrique Gómez Carrillo. ${ }^{2}$ Basten como signos de esa amistad intelectual dos situaciones que alcanzan el carácter de gestos de complicidad: Machado dedicó "Una pasión", de su libro El amor y la muerte (capitulos de novela), "Al admirable psiquiatra Dr. José Ingenieros". 3 El autor argentino, por su parte, se hizo retratar, durante el viaje que nos ocupa, con el sombrero y la capa de Manuel Machado, en una fotografía muchas veces reproducida y que ilustra el tomo VIII de sus obras completas (Ingenieros, 1962).

${ }^{2}$ En su estudio sobre Manuel Machado, Gordon Brotherston menciona que, entre los muchos latinoamericanos que pasaron por Madrid, este poeta estableció vinculaciones personales no sólo con Darío, Nervo o Santos Chocano, sino también con otros como el mexicano Joaquín Casasús y el argentino José Ingenieros, con el cual solía encontrarse en la casa de Cándida Santa María de Otero, visitada también por Villaespesa y Cristóbal de Castro (Brotherston, 1968: 27). Véase también la "Introducción" de Rafael Alarcón Sierra a su edición de los poemas de Machado (2000: 10 y ss.).

${ }^{3}$ El relato, cuyo tema es la pasión de un bibliófilo, fue publicado inicialmente en La correspondencia de España (30.III.1902) y está incluido en la edición de Cuentos completos de Manuel Machado (1999: 55-62), donde se puede apreciar la dedicatoria. 
Quizá sean estas complicidades personales las que expliquen la inclusión, en la crónica de Ingenieros, del verso de Machado, que había visto la luz poco tiempo antes. Cabe recordar que la crónica de Ingenieros está fechada en Madrid en noviembre de 1905 -salió en La Nación el 3 de diciembre- y que el verso citado pertenece a la primera parte del poema machadiano "La Fiesta Nacional", publicada bajo el título de "Rojo y negro" en ese mismo año de $1905 .{ }^{4}$

La fusión del lujo y la naturaleza que se produce en el verso de Machado, parece expandirse en las imágenes que Ingenieros emplea para describir el espectáculo, la pose del torero e, incluso, el aspecto y conducta del animal:

...heroicamente, como dardo que parte de un arco tendido por invisible mano, el toro irrumpe unánime cuando estallan los obscuros resortes donde conspira su instinto. Así una ola, encrespada por el ciclón, va a romper su cresta aborujada contra la negrura de las peñas. (Ingenieros, 2009: 175)

De estas imágenes que evocan las fuerzas naturales, nuestro autor pasa a representar al toro como una alegoría del luchador idealista comprometido con una causa perdida. Dice que al animal "le acoyunda" la realidad al ser rodeado por el torero y sus ayudantes (Ingenieros, 2009: 175), por más que su afán belicoso lo convierta en un héroe solitario, un ejemplo del individualismo heroico al estilo de Don Quijote. Precisamente con este personaje es comparado el toro, transfiriendo, a la inversa, al grupo humano que trajina en el redondel de arena, las cualidades de la animalidad:

...Cuando consigue amedrentar a la traílla humana, cuyo poder sólo está en el número y en el engaño, los capeadores desaparecen ágilmente tras la barrera; él, en su ceguera de ilusorios heroísmos, pone el furor de innúmeras cornadas sobre las tablas crujientes de miedo y de admiración. Así un glorioso manchego -toro del ideal, a su manera- esparció en otra edad sus lanzas sobre insensibles aspas de molino. (Ingenieros, 2009: 175)

\footnotetext{
${ }^{4}$ Rafael Alarcón Sierra historiza las distintas etapas de escritura y publicación de este poema, que reseñamos brevemente aquí: El 22 de abril de 1905, apareció en la revista Blanco y negro bajo el título "La Fiesta nacional". En ese mismo año pero con el título "Rojo y negro", se incluyó en el libro Caprichos, aunque fue suprimido en las ediciones de ese poemario posteriores a 1908. En ambos casos se trataba de la primera sección del texto que luego se conocería como La Fiesta Nacional (Rojo y negro), cuya primera edición completa apareció entre mayo y junio de 1906, en plaquette, dedicado al maestro Antonio Fuentes y que luego sería incluido en el libro El mal poema, de 1909, del que también sería eliminado después. Además, parece que Machado escribió La Fiesta nacional en París, en 1900, y que el poema fue traducido al francés por Laurent Tailhade antes de publicarse en España (Alarcón Sierra en Machado, 2000: 87-95, 280 nota 26).
} 
En su resistencia frente a la muerte, el animal es equiparado con célebres personajes literarios: "El toro embiste y muere, admirable Don Quijote del impulso, rey Lear de su raza" (Ingenieros, 2009: 176). Incluso se convierte en portador de atributos de belleza, descriptos mediante esa retórica de estilo suntuario y preciosista que llegó a ser característica de gran parte del modernismo. Ingenieros dice que sus heridas son "copiosas como rojas Castalias" (2009: 175), o hace referencia a la sangre en estos términos:

La sangre tiene elocuentes esplendores sobre su antepecho; parece una belígera condecoración. De lejos, cuando el toro corre veloz, el manchón de sangre semeja el tapiz carmesí de una dogareza veneciana tendido sobre la quilla de un Bucentauro que vuela a todo viento. A ratos se cuaja en pedazos la hemorragia, como si a la sangre le remordiera abandonar las arterias donde solía pulsar robustamente. (2009: 175)

Lo antedicho no impide que aparezcan en la crónica profusión de términos técnicos de la tauromaquia: se habla del "beluario", las "picas", las "banderillas", las "capas", la "muleta", el "matador", la "estocada a volapie", etc., o se abunda en la mención de nombres de toreros famosos. Sin embargo, aun las alusiones a la técnica del toreo quedan subordinadas a una valoración del espectáculo eminentemente estética, hasta el punto de que la imagen del espada es evaluada en cuanto a su potencial como materia del arte y el cronista reflexiona acerca de los modos de representación más adecuados para eternizar el bello "gesto" que contempla:

El beluario -Bombita, Fuentes, Algabeño, o Machaquito- tiene momentos sublimes. Hay en él gracia de artista y temple de antiguo espartano. Su gesto, cuando es exacto, supera las más hermosas actitudes de la Duse y de Sarah, vale el de cualquier "Discóbolo" griego. Los magníficos emperadores de la antigua Roma hubiéranle proclamado semidiós. Canova habría podido extraer del mármol un "torero que entra a matar" digno de sus intensos "luchadores" que parecen divertir a Perseo en el Belvedere. Falta esa obra maestra en la escultura, la piedra o el bronce de ese gesto soberbio, que es una síntesis del arrojo y una apoteosis de la temeridad. En él tendría su icono el "culto del coraje", si llegara a instituir ritos. La pintura ha vertido cien veces en la tela esta silueta del espada señalando al toro; pero ella es inferior a la escultura tratándose de expresar un bello gesto. (Ingenieros, 2009: 176)

En primer lugar, notemos en este párrafo la equiparación del torero con un artista, más especialmente un actor, al compararlo con las célebres Eleonora Duse y Sarah Bernhardt. En segundo término, del gesto vivo de la actuación se pasa al representado en las artes plásticas, la pintura y la escultura, entre las cuales Ingenieros parece decantarse por la segunda, exhibiendo esa "nostalgia de la escultura" que Octavio Paz atribuía a los parnasianos (1969: 31). Por último, la mención al "culto 
del coraje", al cual le niega la posibilidad de instituir ritos, parece contradecirse con el hecho de dedicar la crónica entera a una práctica como la tauromaquia. Este rechazo a institucionalizar el culto del coraje preanuncia lo que será, años más tarde, su empeño en desmitificar la figura del gaucho Juan Moreira, que tanto protagonismo había cobrado en torno al Centenario de la independencia argentina. ${ }^{5}$

El valor estético es lo que justifica, a los ojos de este viajero, el gusto por las corridas en España, que explica diciendo: "Entendemos que el problema no es matar de una sola estocada, sino matar con arte" (Ingenieros, 2009: 177). No podemos, en este punto, dejar de comparar la perspectiva de Ingenieros sobre la tauromaquia con la del propio Rubén Darío, quien también viajó a España como corresponsal del diario La Nación de Buenos Aires y escribió una serie de crónicas, fechadas entre el 8 de diciembre de 1898 y el 7 de abril de 1900 y que en 1901 pasaron a integrar el libro España contemporánea, dedicado a Emilio de Mitre y Vedia, director de La Nación y la misma persona que años después comisionó a Ingenieros el envío de crónicas desde su periplo europeo. Entre los escritos darianos hay uno muy interesante dedicado al mismo tema de los toros, fechado el 6 de abril de 1899. En esa crónica, la tauromaquia es igualmente equiparada con un arte, pues Darío menciona al torero Ángel Pastor, retirado del oficio a causa de una fractura en el brazo, en estos términos: "Y habla también Pastor de lo malo que hoy anda el toreo, de la decadencia del arte, de lo clásico y de lo moderno, como hablaría un profesor de Literatura o de Pintura" (Darío, [1901]: 108).

Líneas arriba mencionamos el parnasianismo y ciertamente podríamos encontrar en la crónica de Ingenieros huellas de una actitud que se suele asociar con ese movimiento y que más tarde sería constitutiva de buena parte del modernismo hispa-

${ }^{5}$ Cabe aquí recordar que el Juan Moreira de Eduardo Gutiérrez fue publicado inicialmente como folletín en La Patria Argentina, entre noviembre de 1879 y enero de 1880 . Pasó luego al libro, al circo criollo y hasta tuvo una versión lírica, en la ópera Pampa, de Arturo Berutti y Guido Borra, estrenada en 1897. Como señala Adolfo Prieto, para los receptores contemporáneos folletín/novela/drama habrían conformado un continuum que subsumiría las distintas versiones literarias y dramáticas en un mismo fenómeno de recepción. Ingenieros cuestionaba este éxito masivo de Juan Moreira, para desactivar la ética, inaceptable en su opinión, propugnada por el personaje. Buscando desacreditar esta creación literaria y sus efectos ideológicos y sociales, retrocedió hasta lo que consideraba el origen de la ficción: la biografía del personaje histórico. En una conferencia pronunciada en 1910, cuyo resumen fue publicado en los Anales de Psicología, que él mismo dirigía, Ingenieros arremetió contra Juan Moreira, ofreciendo una versión diferente a partir de los registros policíacos de las andanzas del sujeto histórico que había dado pie al personaje de ficción. Con ellos procuró poner de relieve lo que veía como una falacia biográfica y denunciar cómo en el seno de instituciones modernas -el periodismo, la novela- había tenido lugar el nacimiento de una figura tan mitológica como retrógrada, si se la miraba desde los términos en que él estaba tratando de diseñar la cultura argentina. (Prieto, 1988: 60; Ingenieros, 1911: 149-150). 
noamericano: cierta tendencia hedonista liberada de imposiciones morales, la defensa del arte por el arte, la sublimación heroica de lo real, la subordinación de la ética a la estética, una tendencia al objetivismo estetizante según el cual la belleza no residiría en la pasión o el sentimiento, en la verdad ni en la elocuencia, sino en la sugestión, el poder de evocar ciertas imágenes o estados particulares del alma. ${ }^{6}$ En su aceptación de la corrida en tanto que ejercicio estético -"matar con arte"- Ingenieros se muestra alineado con la opinión de Darío, el cual trae a colación un pasaje de Gautier para refrendar la defensa del cruel espectáculo en función del goce estético que procura:

"Se ha dicho y repetido por todas partes que el gusto por las corridas de toros se iba perdiendo en España, y que la civilización las haría pronto desaparecer; si la civilización hace eso, tanto peor para ella, pues una corrida de toros es uno de los más bellos espectáculos que el hombre puede imaginar". ¿Quién ha escrito eso? El gran Theo, el magnífico Gautier, que vino "tras los montes" a ver las fiestas del sol y de la sangre [...] (Darío, [1901]: 103-104).

La referencia dariana a Gautier, figura medular del parnasianismo, puede ayudarnos a establecer la filiación de la clase de descripciones, estetizantes y amorales, que propugna Ingenieros. Es evidente que para Darío la corrida es aceptable en tanto que evento estético: dice que se trata de un "espectáculo [...] suntuoso", que "del vasto circo en que operan esos juglares de la muerte [...] se desprenden un aliento romano y una gracia bizantina." Por ello, afirma, "los que habéis leído descripciones de una corrida o habéis presenciado ésta, no podéis negar que se trata de algo cuya belleza se impone" (Darío, [1901]: 104). El propio Gautier afirmaba que los escritores sensibles que creían que se estaba perdiendo el gusto por las corridas, no tenían más que desplazarse un lunes, entre las cuatro y las cinco, a la puerta de Alcalá, para comprobar que ese "feróce divertissement" no estaba en vías de perderse (Gautier, 1881: 72).

En cuanto al exotismo en la elección de los temas -que se blandía como una acusación sobre los parnasianos y del cual podría ser una modalidad el tópico de la corrida de toros, sobre todo si se piensa que Ingenieros escribe para el público de Buenos Aires-, podría entenderse también como la forma literaria que adoptaba un cierto cosmopolitismo. Una marca de este cosmopolitismo es la sintonía entre esta

${ }^{6}$ La adopción del principio parnasiano del l'art pour l'art, "haciendo suya la respuesta que ante una transformación similar habían opuesto casi cuarenta años antes los poetas europeos" fue, al decir de Ángel Rama, la solución estética dominante del modernismo hispanoamericano. Esta estética se ponía al servicio de dos valores "siempre vagos y mal definidos": el ideal y la belleza. Aunque insistimos en que no fue la única posibilidad de expresión de los modernistas, es notable la influencia de estos valores estéticos en pasajes del texto que analizamos (Rama, 1970: 46-47). 
crónica dedicada a la costumbre o tradición de la lidia de toros y lo que decían guías para viajeros consagradas por aquel entonces, como la que nuestro autor llama, en otra crónica, "el democrático Baedeker" (Ingenieros, 2009: 102). Esa afamada guía de turismo, pensada para un público cosmopolita, ubicaba las corridas de toros entre los espectáculos recomendados de España, como el teatro nacional. Y en ella podemos leer algunas ideas afines a la posición de Ingenieros: el toreo es una costumbre un tanto bárbara pero vestigio de antiguas tradiciones heroicas e, incluso, cortesanas, y su práctica es inversamente proporcional al grado de desarrollo industrial y comercial de las distintas ciudades españolas.

Por último, diremos que si bien la elección de temas exóticos o costumbristas había pasado de los románticos a los parnasianos, y de estos a los modernistas, los dos últimos le imprimían una modulación diferente a la cuestión al exacerbar la separación, la distancia contemplativa, respecto de ese objeto exótico convertido en tópico literario y representado estéticamente (Davison, 1971: 50). ${ }^{8}$

\section{La mirada cientificista}

La distancia objetivante se percibe con más claridad cuando se pasa al problema de la justificación moral del tópico, que Ingenieros, como en el resto de su producción, aborda desde su perspectiva medicalizada y cientificista. ${ }^{9}$ Su explicación es casi un diagnóstico donde el enfermo es un país entero, España, presentado como una región que de algún modo ha visto disminuidos su vigor y su voluntad:

Todos los agotados poseen su agradable veneno. El poeta gastado reanima su llama, parpadeante ya, con el verde tósigo de su ajenjo. El viejo exhausto busca paraísos artificiales en frágiles excitantes que renuevan estremecimientos fugitivos. El luchador acoquinado pide al alcohol la sensación completa de su yo vacilante, para centuplicar el coraje perdido. El escritor tiene el tabaco para el cerebro cansado; el financista lubrifica con té o café su engranaje mental enmohecido por los cálculos; el amante compensa con la estricnina su asiduidad imprevisora. Todos fomentan esa ficción de la propia energía, contentándose con la sombra de un gesto que no existe.

\footnotetext{
${ }^{7}$ Se trata de la crónica "Sobre las ruinas I", fechada en Italia.

${ }^{8}$ Para algunas de las referencias al parnasianismo que efectuamos aquí, remitimos al artículo de Paul Bourget (1905).

${ }^{9}$ Cuando hablamos de cientificismo, nos referimos a la extensión, no siempre pertinente, del método de las ciencias naturales a todos los campos de estudio. Esta extrapolación metodológica está acompañada por la impronta de una retórica que no siempre traduce un conocimiento científico efectivo sino que es, en gran medida, un efecto discursivo.
} 
El símil fuerza la idea. Este pueblo que se apiña y se excita en el populoso tendido, bajo el sol meridional que pone luz y fuego en las graciosas mantillas, que pone hervores de fiebre y de sangre en los corazones, es un pueblo enfermo de pereza y de inercia. Conserva el labio propicio a la amable sonrisa y a la algazara bulliciosa. No es la risa plena y sonora que llena la boca del hombre sano y fuerte; más bien recuerda la alegría optimista del tísico en vísperas de partir. Pero le falta lo esencial, la voluntad, la aptitud para la acción organizada y persistente. (Ingenieros, 2009: 177)

Esta incapacidad o falta de inclinación por el trabajo es, para Ingenieros, síndrome de una verdadera enfermedad social. En su apoyo, y para que no se lo acuse de parcialidad, cita las palabras de Eusebio Blasco, a quien califica como "escritor ibérico y ultramadrileño": "Todo, menos trabajar: esta es la teoría española, y, sobre todo, la madrileña" (Ingenieros, 2009: 177). En eso, continuaba el pensamiento de quienes, como Max Nordau, consideraban la incapacidad para el trabajo como una marca o síntoma de la degeneración. ${ }^{10} \mathrm{Y}$ en el contexto del alienismo rioplatense, recordemos que ya desde el siglo XIX, en las instituciones manicomiales, la capacidad de trabajar se consideraba directamente proporcional al grado de cordura (Vezzetti, 1985: 44 y ss., 75 y ss.).

Según la ya mencionada guía Baedeker, tan citada por Ingenieros y otros cronistas viajeros de entonces, las corridas de toros habían sido en el pasado un ejercicio cortesano que ahora se había convertido en un deporte más profesional (Baedeker, 1898: XXVI-XXVII). ${ }^{11}$ La diferencia entre la cantidad de corridas, plazas de toros y envergadura de los espectáculos también era una marca señalada por el Baedeker, texto que daba por sentada la relación entre el auge de este espectáculo y el subdesarrollo económico de algunas regiones. ${ }^{12}$ Se infiltraba en estas explicaciones la idea

${ }^{10}$ Por ejemplo, uno de los argumentos mediante los cuales Nordau desestimaba la estética de los simbolistas era su acusación de que ninguno de ellos tenía oficio conocido, porque, en su opinión, esos "degenerados" eran tan incapaces de cumplir con una ocupación regular como del aprendizaje metódico (Nordau, 1993: 102).

${ }^{11}$ En el capítulo VI de la célebre novela Sangre y arena de Vicente Blasco Ibáñez, publicada tres años después de la crónica que nos ocupa, el personaje del doctor Ruiz expone una historia del toreo en similares términos y, curiosamente, presenta la popularización de esta práctica, antes reservada a la nobleza, como un progreso, porque había sustituido a los grandes espectáculos populares de la edad media: los autos de fe de la inquisición, cuyas víctimas eran humanas (Blasco Ibáñez: 159-160). De la misma opinión es Sarmiento, quien llega a afirmar que los autos de fe "eran las corridas de toros que a su modo daba la inquisición" (Sarmiento, 1993: 142).

${ }^{12}$ Según la guía Baedeker, las corridas de toros eran más frecuentes en la España central y del sur. Por el contrario, en la España del Norte y en Cataluña, "where trade and industry flourish", los espectáculos tauromáquicos eran excepcionales y quedaban reservados a las ferias anuales (Baedeker, 1898: XXVI-XXVII). 
de la decadencia de una práctica, originalmente noble y aristocrática, que había llegado a convertirse en un espectáculo primitivo adecuado al gusto de las multitudes. Esta idea de la tauromaquia como una práctica retrógrada, decadente en el sentido cultural, aunque consustancial al ambiente español, ya aparecía en la citada crónica de Rubén Darío, quien sentenciaba: "Decadentes o no decadentes, los toros seguirán en España. No hay rey ni Gobierno que se atreva a suprimirlos" (Darío, [1901]: 105). Algo similar a lo que, más de medio siglo antes, había señalado Domingo Faustino Sarmiento en ocasión de su viaje a la península ibérica; según podemos leer en la carta que escribió para Victorino Lastarria y en la que reúne sus impresiones sobre España, la inclinación española por las corridas de toros es cruel herencia de la época romana:

\begin{abstract}
...Por sus costumbres i su espíritu, el pueblo español es el pueblo mas romano que existe hoi dia. Todos sus males le vienen de ahí; enemigo del trabajo, guerrero, heróico, tenaz, sobrio, i apasionado por los espectáculos todavía pide panen et circenses para vivir feliz en medio de su caida. Los sangrientos combates de bestias feroces han luchado veinte siglos con el cristianismo i han triunfado de él, como los toreadores lo hacen de los mas temibles bichos. Sobre la plaza de toros el pueblo español es grande i sublime; es pueblo soberano, pueblo rei tambien. Allí se resarce, con emociones mas vivas que las del juego, de las privaciones a que su pobreza lo condena, i si esta diversion puede ser acusada de barbarie i de crueldad, es preciso convenir, sin embargo, que no envilece al individuo como la borrachera, que es el innoble placer de todos los pueblos del norte. [...] (Sarmiento, 1993: 139-140) ${ }^{13}$
\end{abstract}

Al decir de Ingenieros, es un pueblo enfermo, entonces -y cuya enfermedad se asocia a la falta de productividad-, el que disfruta en el espectáculo de la tauromaquia: "Todos van a la plaza de toros tras el veneno que excita el alma de la raza,

${ }^{13}$ La carta está fechada el 15.XI.1846. Cabe aclarar que en ella también observamos la dualidad presente en Ingenieros, una crítica sociológica aunada a la seducción estética que ejercen sobre el viajero los espectáculos de las corridas de toros, como se puede apreciar en el siguiente pasaje, en el que Sarmiento compara el arte del torero con manifestaciones artísticas, como la música: "A estos primeros pases se siguen diez diversos, cual variaciones de un tema único que es la muerte, i cuyas melodías se componen de coraje, actitudes artísticas, destreza i sangre fría. El público español mudo, estático, hasta entonces, no por efecto del miedo, que no conoce, sino por la profunda emoción que le inspira el sentimiento del arte, prorrumpe en pos de aquellas brillantes fiorituras, en gritos apasionados que conmueven los edificios de la plaza [...]" (Sarmiento, 1993: 145). Como el mismo autor sintetiza, "los toros" son un "Espectáculo bárbaro, terrible, sanguinario, i sin embargo, lleno de seducción i de estímulo" (Sarmiento 1993: 147). 
llena ya de languideces y nostalgias" (Ingenieros, 2009: 178). ${ }^{14}$ Esas "nostalgias", como es propio de toda decadencia, ubican en el pasado el vigor perdido del cual la corrida actual es un mero eco:

El valor dormido ha siglos, el de las grandes horas históricas, parece despertar en la bravura aparente de los gritos, los aplausos, los tumultos; diríase que una partícula de Cides y Pelayos permanece todavía en esos corazones enfermos de pereza. (Ingenieros, 2009: 178)

También Darío, siguiendo en ese punto a Theophile Gautier, afirma que los observadores de una corrida de toros conforman "un público de excepción cuyo igual no sería posible encontrar sino retrocediendo a los circos de Roma" (Darío, [1901]: 105 , nuestra la bastardilla).

Después de este diagnóstico de la enfermedad social, nuestro médico-escritor justifica la función paliativa, ya que no curativa, de este espectáculo:

Conociendo al pueblo español, nadie osará suprimir los toros en España. ¿Para qué? Sería cruel, inhumano, condenar a este enfermo a vivir sin su agradable morfina. Los toros le son indispensables, como al francés el ajenjo y al inglés el whisky. (Ingenieros, 2009: 178)

De ahí la aparente ambigüedad de esta crónica, que cuestiona moral y socialmente lo que defiende estéticamente:

Declamar contra los toros, desde lejos y sin conocerlos, es una de tantas ingenuidades propias de hombres que desean demostrar a los demás su espíritu de progreso y su afán de componer los innumerables entuertos humanos. La verdad está en los hechos y no en las doctrinas aprioristas; cada pueblo tiene enfermedades que le son propias y se busca los remedios o paliativos que mejor le cuadran. Ese es el criterio moral del asunto. (Ingenieros, 2009: 178)

${ }^{14}$ Sobre la imprecisión del término "raza", cabe aclarar que en la época se trataba de una confusa noción que recubría conceptos tanto histórico-culturales como biológicos, en una tradición intelectual bastante heterogénea que abrevaba en el romanticismo, el positivismo, la sociología evolucionista y la mayor parte de las corrientes de pensamiento de la época (Real de Azúa, 1987: 164).

${ }^{15}$ No deja de ser algo simplista atribuir esta valoración de Ingenieros a toda España. Como se puede apreciar en su libro La cultura filosófica en España, la región que comprende a Aragón, Cataluña y Valencia, que él llama "esta Cataluña grande", exhibe costumbres de otro tenor, que el autor asocia con una "tradición del pensar hondo y vasto" (Ingenieros, 1962: 26). 
El factor experiencia se convierte aquí en la piedra de toque frente al saber de las "doctrinas" teóricas, incluso de aquellas consideradas progresistas. En esta preferencia por la experiencia concreta frente a la abstracción hay, evidentemente, una actitud cientificista, de cuño positivista. Pero también es claro ejemplo de la posición de tantos cronistas modernistas en su defensa del "derecho a la subjetividad". Buscando diferenciarse de los reporters -sobre todo los norteamericanos- que obedecían a los criterios de objetividad y realismo, los chroniqueurs de tradición francesa, que fueron secundados por los cronistas latinoamericanos del período, acentuaron un estilo que daba lugar a la experiencia individual y la emoción subjetiva, a medio camino entre la mera información y el artículo doctrinario o editorial (Rama, 1970: 67-68, 70; Rotker, 2005: 111, nota 31 y 128). La experiencia de un sujeto libre de prejuicios incluso de aquellos valores positivos asociados a la modernización y el progreso- es lo que Ingenieros procura poner en primer plano cuando afirma:

El criterio estético no admite disyuntivas. Quien guste de bellezas y de emociones, quien admire el gesto y el valor, vaya a España y asista a una buena corrida. Diga después su impresión, honestamente, como si no temiera ser oído, con el nihilismo moral indispensable para ser sincero sin sujetarse a preocupaciones y a sentimentalismos.

Ese hombre libre podrá afirmar que la morfina de España produce una emoción magnífica, en la cual se funden la alta voluptuosidad de la belleza y la vigorosa embriaguez de la energía.

Huelga demostrar que los pueblos jóvenes y vigorosos no necesitan morfina. (Ingenieros, 2009: 178)

Esta última frase hace referencia, obviamente, a la Argentina, que Ingenieros visualizaba como un país en formación, con una raza joven y sana y a la que auguraba un porvenir de dominio en Sudamérica. En este punto de la crónica observamos cómo la reflexión sobre la corrida forma sistema con las ideas socio-biológicas de Ingenieros. Si a mediados del siglo XIX, los términos civilización y Europa moder$n a$ eran tratados como equivalentes, dejando a las demás sociedades el lugar de predecesoras deficientes o imitaciones defectuosas de ese original, a fines de siglo los estudiosos ya aplicarían regularmente los términos "decadencia", "decrepitud" y "degeneración" a la propia Europa. Y ello porque la evolución significaba que la historia natural de las especies, incluidos los seres humanos, ya no era fija e inmutable; pero mientras ese cambio podía implicar el ascenso o mejoramiento de las especies a través del tiempo, también podía causar, como en el caso de los antiguos imperios y civilizaciones, su declinación y caída (Herman, 1998: 47, 118). Apoyándose en parte en esta clase de interpretaciones seudo-científicas sobre el ascenso y decadencia de las sociedades, Ingenieros interpreta la corrida de toros como evidencia de un proceso biológico-social en que el envejecimiento de una población se hace 
patente en virtud de la pervivencia de costumbres y gustos atávicos. ${ }^{16}$ Una opinión, en síntesis, del tenor de la que sostenía Manuel Ugarte cuando dictaminaba:

Cuando un hombre empieza a tener costumbres, es que ha llegado al máximum de su crecimiento: ya no se puede esperar de él más que repeticiones. Cuando un pueblo empieza a tener tradiciones, es que ha dado ya todo lo que podía, y entra en el período del descenso. España tiene muchas tradiciones, demasiado plomo en las alas. (Ugarte, 1904: 86-87)

\section{Comentario final}

No es inusual, entre los cronistas del período, la extrapolación de cuestiones doctrinales, la disertación erudita a partir de paisajes, espectáculos o anécdotas puntuales. En sus Crónicas del bulevar, Manuel Ugarte explica cómo trabaja el cronista cuando oficia como corresponsal desde el extranjero y expone estas prácticas razones:

...cuando la correspondencia está destinada a países lejanos, las páginas llegan casi siempre marchitas y sin interés, porque el telégrafo las ha precedido de veinte días y se ha encargado de borrar cien veces la impresión del suceso que se relata. [...] Por eso se ven obligados los que escriben a elegir temas un tanto vagos, susceptibles de generalización y de comentario ajeno a la actualidad. [...] El cronista se ve en la necesidad de refugiarse en paisajes morales y apreciaciones imprecisas. (Ugarte, 1903: 18)

Como ya se dijo, Ingenieros escribe ésta y otras "correspondencias", como él las llama, al estilo de un cronista y no de un reportero. La previsión de un lector distante y que recibirá la noticia con retraso, le da ocasión para la disertación doctrinal, no "imprecisa", como dice Ugarte, pero que sí apunta a la generalización y el orden moral. La crónica se estructura, en conclusión, en torno de dos ejes: uno estético, que procura comentar y comunicar los goces, la fruición de disfrutar una corrida de toros, y otro de corte sociológico, que busca explicar la pervivencia de costumbres como la tauromaquia en una época marcada por el afán de progreso, explicación que es tributaria del discurso sobre el orden social escrito en el lenguaje de las ciencias biológicas, como ya lo indica de alguna manera el título de la crónica y como

${ }^{16}$ La expresión atavismo, derivada de atavus, antepasado remoto, era empleada por los biólogos del siglo XIX para referirse a la supervivencia de atributos o inclinaciones bestiales en organismos y sociedades contemporáneas. Se decía que todo organismo tenía algunas características perdidas que podían reaparecer en ciertas condiciones y se legarían a los descendientes. La teoría atavista existía antes de Darwin, pero su teoría de la evolución parecía confirmarla, al igual que la genética mendeliana posteriormente. El atavismo sería la piedra fundamental de la teoría de la degeneración (Herman, 1998: 119-120). 
no podría ser de otro modo en Ingenieros. ${ }^{17} \mathrm{Y}$ ello es así porque, en el contexto argentino, el recurso al cientificismo para orientar las políticas sociales convirtió al biologicismo en un lenguaje común para las propuestas de diverso signo ideológico que buscaban legitimación intelectual, máxime en el caso de alguien formado en las disciplinas de las ciencias médicas y biológicas, como era el caso de Ingenieros.

Por otro lado, parece razonable preguntarnos por la clase de mirada, dentro del amplio espectro de las miradas modernas, que se le puede asignar a Ingenieros, entendiendo esas miradas como "posiciones de locución" que exhiben y/o ocultan, a su vez, posiciones políticas y problemáticas ideológicas y estéticas (Rodríguez Pérsico, 2008: 33). Es ya un lugar común asociar la mirada del cronista latinoamericano del entresiglo XIX-XX con la del pintor de la vida moderna, según la clásica definición de Baudelaire: "il est le peintre de la circonstance et de tout ce qu'elle suggère d'éternel" (Baudelaire, 1889: 54). En este caso particular, al pintar la corrida de toros como una circunstancia pero, simultáneamente, como un evento del cual se pueden extrapolar conclusiones de alcance social más general, la escritura de Ingenieros ejemplifica una modalidad específica de las miradas modernas: la del sabio, que, bajo la superficie del goce estético generado por el espectáculo, puede hurgar en las causas profundas de los hábitos y costumbres de la ciudad de Madrid, leídos como síntomas de salud o enfermedad del cuerpo social.

\section{BIBLIOGRAFÍA}

BAEDEKER, Karl.

1898 Spain and Portugal. Handbook for Travellers. Leipsic: Karl Baedeker Publisher. Internet Archive:

http://www.archive.org/stream/spainandportuga02firgoog\#page/n11 /mode/1up [consulta efectuada el 12/7/2010]

BAUDELAIRE, Charles.

1889 "Le peintre de la vie moderne" [1863], dans Oeuvres complètes de Ch. Baudelaire. L'art romantique. Paris: Alphonse Lemerre, pp. 54-105. Internet Archive:

http://www.archive.org/details/oeuvrescompltes00baudgoog [consulta efectuada el 30/3/2010]

${ }^{17}$ Michel Foucault explica cómo, a partir del siglo XIX, el lenguaje médico desplazó significativamente al lenguaje jurídico para pensar las relaciones políticas y sociales. Eso se debió a que el discurso que, desde el pensamiento histórico-político inglés y francés de los siglos XVII y XVIII, había entendido la guerra de razas como el sustrato de las relaciones sociales, fue paulatinamente capitalizado por los biólogos racistas y eugenistas de fines del siglo XIX, dando lugar al nacimiento de una biopolítica (Foucault, 1996). 
BLASCO IBÁÑEZ, Vicente.

1943 Sangre y arena. Buenos Aires-México: Espasa-Calpe. BOURGET, Paul.

1905 "L'esthétique du Parnasse", dans Études et Portraits. Portraits d'écrivains et Notes d'esthétique. Paris: Librairie Plon, pp. 243 258. [En línea] Gallica. Bibliotèque Numérique. Bibliothèque Nationale de France:

http://gallica.bnf.fr/ark:/12148/bpt6k801702.image.r=paul+bourget [consulta efectuada el 16/7/2010]

BROTHERSTON, Gordon.

1968 Manuel Machado. A revaluation. London: Cambridge UP. DARÍO, Rubén.

[1901] “¡Toros!”, en España contemporánea. Volumen XIX de las obras completas. Madrid: Mundo Latino, pp. 103-111. Internet Archive: http://www.archive.org/details/obrascompletaspr19daruoft [consulta efectuada el 30 de junio de 2010]

DAVISON, Ned.

1971 El concepto de modernismo en la crítica hispánica. Buenos Aires: Nova. FOUCAULT, Michel.

1996 Genealogía del racismo. Trad. de Alfredo Tzveibel. La Plata: Altamira, [1975-1976].

GAUTIER, Théophile.

1881 "VII. Courses de taureaux. Sevilla le picador. La estocada a vuela pies", en Voyage en Espagne. Tras los montes. París: G. Charpentier, pp. 71-88, [1843]. [En línea] Gallica. Bibliotèque Numérique. Bibliothèque Nationale de France:

http://gallica.bnf.fr/ark:/12148/bpt6k56855443.r=.langES [consulta efectuada el 15/7/2010]

HERMAN, Arthur.

1998 La idea de decadencia en la historia occidental. Trad. de Carlos Gardini. Santiago de Chile: Andrés Bello.

INGENIEROS, José.

1911 "La psicología de Juan Moreira", Anales de Psicología, Vol. II, pp. 149-150.

1962 Obras completas. Tomo VIII. Buenos Aires: Mar océano.

2009 Las crónicas de José Ingenieros en 'La Nación' de Buenos Aires. Ed. de Cristina Beatriz Fernández. Mar del Plata: Martin-UNMDPANPCyT.

JIMÉNEZ, José Olivio.

1993 "El ensayo y la crónica del modernismo", en Historia de la literatura hispanoamericana. Tomo II. Del neoclasicismo al modernismo. Coord. de Luis Iñigo Madrigal. Madrid: Cátedra, pp. 537-548. 
MACHADO, Manuel.

1999 Cuentos completos. Ed., pról. y notas de Rafael Alarcón Sierra. Ilustraciones de Marina Arespacochaga. Madrid: Clan.

2000 Alma. Caprichos. El mal poema. Ed. de Rafael Alarcón Sierra. Madrid: Castalia.

NORDAU, Max.

1993 Degeneration. Translated by George Mosse. Lincoln-London: Nebraska UP, [1892].

PAZ, Octavio.

1969 Cuadrivio. Dario, López Velarde, Pessoa, Cernuda. México: Joaquín Mortiz.

PRIETO, Adolfo.

1988 El discurso criollista en la formación de la Argentina moderna. Buenos Aires: Sudamericana.

RAMA, Ángel.

1970 Rubén Dario y el modernismo. Circunstancia socioeconómica de un arte americano. Caracas: Ediciones de la Biblioteca de la Universidad Central de Venezuela.

REAL DE AZÚA, Carlos.

1987 “Ambiente espiritual del 900”, en Escritos. Montevideo: Arca, pp. $145-165$.

RODRÍGUEZ PÉRSICO, Adriana.

2008 Relatos de época. Una cartografía de América Latina (1880-1920). Rosario: Beatriz Viterbo.

ROTKER, Susana.

2005 La invención de la crónica. México: FCE-Fundación para un Nuevo Periodismo Iberoamericano.

SARMIENTO, Domingo Faustino.

1993 Viajes. Ed. crítica, Javier Fernández (coord.). Madrid: Colección

Ugarte, Manuel. Archivos-FCE-CSIC.

1903 Crónicas del bulevar. Pról. de Rubén Darío. París: Garnier Hermanos. Internet Archive:

http://www.archive.org/details/crnicasdelbulev00dargoog [consulta efectuada el 23/3/2010]

[1904] Visiones de España (apuntes de un viajero argentino). Valencia: Sempere.

VEZZETTI, Hugo.

1985 La locura en la Argentina. Buenos Aires: Paidós.

ZIMMERMANN, Eduardo.

1995 Los liberales reformistas. La cuestión social en la Argentina, 18901916. Bueno Aires: Sudamericana-Universidad de San Andrés. 